\title{
Intellectual disability: an approach from the health sciences perspective
}

\author{
Luis Salvador-Carulla, ${ }^{(1)}$ Carmen Rodríguez-Blázquez, ${ }^{(2)}$ Almudena Martorell. ${ }^{(3)}$
}

\section{Salvador-Carulla L, Rodríguez-Blázquez C, Martorell A. Intellectual disability: an approach \\ from the health sciences perspective. Salud Publica Mex 2008;50 suppl 2:SI 42-SI 50.}

\begin{abstract}
Intellectual disability (ID) is a complex condition that has not aroused very much interest in the health sciences and medical fields. As a result, a large part of the responsibility for caring for individuals with ID has fallen in the areas of education, social services and volunteering. Nevertheless, intellectual disability is a very significant health problem, whether because of its prevalence, the costs to the public health system, the families and society in general or due to related health complications. ID should be a priority area of study and action in the health field.This article reviews the conceptual, diagnostic and etiological problems that affect intellectual disability, as well as factors related with the health of the persons who are affected. In addition, some recommendations are outlined for improving health care for this population group.
\end{abstract}

Key words: intellectual disability; health; conceptual framework

\author{
Salvador-Carulla L, Rodríguez-Blázquez C, Martorell A. \\ Discapacidad intelectual: un enfoque \\ desde la perspectiva de las ciencias de la salud. \\ Salud Publica Mex 2008;50 supl 2:SI42-SI50.
}

\section{Resumen}

La discapacidad intelectual (DI) es una condición compleja que no ha despertado gran interés en el campo médico y en el de las ciencias de la salud. Como consecuencia, gran parte de la responsabilidad del cuidado de los individuos con DI ha recaído en las áreas de la educación, el servicio social y el voluntariado. Sin embargo, la discapacidad intelectual es un problema de salud muy significativo,ya sea por su prevalencia, por los costos para el sistema de salud pública, para las familias y para la sociedad en general o debido a las complicaciones de salud relacionadas con ella. La DI debería ser un área de estudio y de acción prioritaria en el campo de la salud. Este artículo revisa los problemas conceptuales, diagnósticos y etiológicos que afectan a la discapacidad intelectual, así como los factores relacionados con la salud de las personas afectadas. Además se delinean algunas recomendaciones para mejorar el cuidado de la salud en este grupo de población.

Palabras clave: discapacidad intelectual; salud; marco conceptual

(I) Section Chair of the "Psychiatry of Intellectual Disability" of the World Psychiatric Association.

(2) Centro Nacional de Epidemiología, Instituto de Salud Carlos III, Madrid (Spain).

(3) Fundación Carmen Pardo-Valcarce, Madrid (Spain). 
$\mathrm{H}^{\mathrm{i}}$ storically, intellectual disability (ID) has received variable attention in developed countries -from charity to the development of specific devices for socialeducational care-.

ID terminology has varied over time. In the past, terms have been used such as "imbecility," "mongoloidism," "mental deficiency" and "mental retardation." Since 2004, there has been a broad consensus in favor of the use of the term "intellectual disability." Prominent international and national associations have already accepted the denomination of this disorder. Thus, the American Association of Mental Retardation (AAMR) has changed its name to the American Association of Intellectual Disability (AAIDD) ${ }^{1}$ and the World Health Organization (WHO) uses this term as a synonym for mental retardation.

No other medical illness exists that brings together the specific characteristics and nuances entailed by the concept of ID, although it has received very little attention on the part of health sciences and health services in general. In fact, in many countries, caring for persons with ID has been limited to the area of social and educational services or social welfare. As an indication of such lack of interest, suffice to say that ID is not included in the World Bank and WHO Global Illness Burden.

There are diverse reasons for this scarce interest. First, there is no international consensus on the definition of intelligence or on how to quantify it. Second, more epidemiological studies are needed about the effect of early cognitive developmental disorders on public health in order to designate priorities and design effective interventions, especially in undeveloped countries. Third, while for distinct psychiatric disorders -from personality disorders to schizophrenia- there is an intense debate about classification criteria, in the area of ID the debate almost exclusively focuses on assigning the appropriate name to the concept and on how to evaluate skills and the kind of support needed. Fourth, there is not a sufficient amount of funds designated for ID research since it is not a key issue in national ID programs and the pharmaceutical industry is not interested in ID research. This creates a vicious circle: since there are no resources for conducting research, not enough scientific research is produced about ID for it to be incorporated into mental health policies based on the evidence, or for improving the classification and diagnosis system (for example, the International Classification of Illnesses ICD-10, Statistical Diagnostic Manual DSMIV) or for devising good practice guidelines or other tools to guide the homogenization of socio-health care. And last, many professionals and families / service users believe that it has more to do with social or educational concepts than with a health condition. ${ }^{2}$

One factor that increases the difficulty in understanding the term ID is the conceptual reference framework. It is not a medical disorder, although it has an illness classification code (for example, International Classification of Illnesses, 10th version, ICD-10, 2002), and it is not a mental illness, although it is included in classifications for mental disorders (for example, the DSM-IV-TR, American Psychiatric Association, 2002). In fact, it is a type of syndrome (a metasyndrome) that is similar to the concept of dementia. ${ }^{2}$

ID has a prevalence of $1.5 \%$ in western countries, although this rate can increase to $4 \%$ in less developed nations ${ }^{3}$ due to factors such as the presence of neurotoxic agents or nutritional deficiencies during pregnancy. A considerable proportion of persons with ID have plurideficiencies and medical problems. In addition, ID has consequences throughout one's lifetime and entails a significant burden for families and caregivers, demanding a high level of service provisions. ID is the principal cause of socio-health expenses, not only in the mental health sector but also in the medical field, at least in western countries. ${ }^{4}$

Due to its importance, it is consequently necessary to deepen the concept of ID from a comprehensive social perspective, without overlooking conceptual, nosological, medical, pharmacological and psychiatric factors.

\section{The concept of intellectual disability}

ID refers to a particular state of intellectual and adaptive functioning, which begins in infancy and in which limitations in intelligence coexist with attenuated cognitive, social and practical skills. The problems and deficits in the subject with ID may have a specific cause, but ID is not synonymous with an etiological factor.

The term ID includes, by definition, three essential components: a) intellectual functioning significantly below average with an intelligence quotient (IQ) less than 70 (measured using psychometric tests such as the Wechsler Intelligence Scales for Children-Revised, StanfordBinet, Kaufman Assessment Battery for Children); b) a marked deficit in the ability of the individual to adapt to the daily demands of their social environment (neither of these factors -low intelligence and deficient adaptive conduct- is sufficient for establishing an ID diagnosis if they are regarded individually); and c) onset before the age of 18. Slight variations exist in the codification of the severity levels for ID, although the important division is that of mild and moderate (IQ greater than 35-40), severe (IQ 20-25 to 35-40) and profound (IQ less 
than 20-25). In spite of the fact that the above divisions are generally agreed upon, the American Association on intellectual and Developmental Disabilities (AAIDD), in their latest definition (2002), ${ }^{5}$ moves away from the importance given to date to the measurement of intelligence, which depends more on the evaluator's judgment than on intellectual tests. In addition, for the purpose of using language that is focused more on needs and less on deficits, the AAIDD proposes a new categorization for ID degrees: the need for intermittent, limited, extensive or generalized support.

It also needs to be clarified that it is necessary to view functional limitations in relation to the social and cultural context of age and cultural peers and to consider cultural and linguistic diversity, as well as differences in communication and sensorial, motor, and behavioral aspects. The fundamental objective for the evaluation and diagnosis of ID is the development of a profile of types of support necessary to enable the improved functioning of persons with ID. Finally, the subjects' abilities and skills that may contribute to such improvement should also be evaluated. ${ }^{3}$

\section{Etiopathogenic and diagnostic factors}

One factor in ID that contributes to conceptual problems is the heterogeneity of the etiological factors, which are summarized in table I. In addition, in $60 \%$ of persons diagnosed, the deficit or alteration that causes ID is not known. In many mild ID cases it is difficult to find a specific, underlying medical cause, although signs appear that would suggest that neurological damage or social deprivation (poverty, malnutrition, etc.) are possibilities. In this respect, Zigler ${ }^{6}$ proposes subdividing the population of persons with ID into those who have suffered an interruption in the maturation process and those who do not reach the level expected in the population, in spite of having completely developed. The first group includes the majority of non-biological causes, especially social deprivation. The second group includes all of the causes that can be characterized as biological, since they are precisely what make average intellectual functioning impossible.

Among the diverse causes of ID, due to its importance it is worth citing genetic anomalies, that make up $30 \%$ of the cases; standing out among these, because of their high prevalence, are trisomy 21 or Down syndrome (one in 800 live births) and fragile $\mathrm{X}$ syndrome (five out of every 10000 births).

Determining the causes of ID is essential for intervention since health care expenses would decrease and the response to treatment and the prevention of pos-
Table I

Principal causes of syndromes THAT ACCOMPANY INTELLECTUAL DISABILITY

Cause Example

Metabolic disorders:

\begin{tabular}{ll} 
Lipids & Tay-Sachs Disease \\
\hline Mucopolysacaridosis & Hurler Syndrome \\
\hline Amino Acids & Phenylketonuria \\
\hline Carbohydrates & Galactosemy \\
\hline Purines & Lesch-Nyhan Syndrome
\end{tabular}

Genetic disorders:

\begin{tabular}{ll} 
Neurocutaneous & Tuberous Sclerosis \\
\hline $\begin{array}{l}\text { Chromosomal alterations: } \\
\text { Trisomy }\end{array}$ & Down Syndrome \\
\hline Linked with X chromosome & Fragile X Syndrome \\
\hline Microdelection & Prader-Willi Syndrome \\
\hline Mutation & Smith-Lemli-Opitz Syndrome
\end{tabular}

External causes:

\begin{tabular}{ll} 
Intrauterine infections & Rubella, Syphilis \\
\hline Toxic substances & Fetal Alcohol Syndrome \\
\hline Perinatal problems & Anoxia, Prematurity \\
\hline $\begin{array}{l}\text { Malnutrition, social } \\
\text { or affective deprivation }\end{array}$ & \\
\hline
\end{tabular}

sible complications would improve. ${ }^{7}$ In this respect, in recent years the term "behavioral phenotype" has been introduced, which is described by Flint and Yule as: "a characteristic pattern of motor, cognitive, linguistic, and social abnormalities that is consistently associated with a biological disorder. In some cases, the behavioral phenotype may constitute a psychiatric disorder; in others, behaviors which are not usually regarded as symptoms of psychiatric disorders may occur". ${ }^{8}$

Knowledge about the behavioral phenotype helps to plan and organize the care of persons with ID. Although the first behavioral phenotypes were nearly exclusively based on syndromes with genetic origins, today it is possible to talk also about behavioral phenotypes for non-genetic conditions that accompany ID -such as fetal alcohol syndrome- which are applicable to the set of ID disorders with biological origins.

It is necessary to take into account that ID can be confused with other syndromes that begin in infancy or that also involve cognitive or social functioning deficits, such as learning or communication disorders (without a connection to ID), where a developmental alteration is observed in a specific area (reading or expressive 
language, for example) but there is not a generalized affect in intellectual development and adaptive skills. In addition, it is necessary to differentiate ID from generalized development disorders that are characterized by a qualitative developmental affectation in social interaction and verbal and non-verbal social communication skills that may or may not be connected with ID.

Furthermore, ID must be distinguished from other syndromes or that are also associated with cognitive dysfunction, such as dementia or cognitive deterioration, but whose diagnosis requires that memory affectation and other cognitive deficits are significantly attenuated in comparison with prior ability levels.

Lastly, limited intellectual ability is described by an IQ interval higher than that required for ID (71-84). It is possible to diagnose ID in individuals with IQ scores between 71 and 75 if they have the characteristic deficit in adaptive behavior. In order to differentiate mild ID from limited intellectual ability, careful review of all of the available information is necessary. ${ }^{9}$

\section{Health and intellectual disability}

Medical advances have enabled persons with ID to live longer and have a better quality of life than in the past. Nevertheless, increased life expectancy has resulted in new medical situations (for example, a higher incidence of dementia) that, when added to the comorbility derived from the very causes of ID, require an in-depth study of medical and health factors related with ID.

This population has many difficulties in terms of access to community health services. In Europe, an appropriate response to this problem was the initiation of Project Pomona, ${ }^{10}$ which has been carried out in European Union countries since 2002. The principal objective of this project is to identify the health indicators, based on evidence, that reflect the most important areas for improving the quality of life of and equal access to health care for persons with ID. This process in identifying factors has been conducted with the participation of subjects with ID, their families, professionals and administrators.

Project Pomona is based on the principal that health is one of the parameters for quality of life. Individuals with ID are citizens who have an inherent right to equal opportunities in terms of health care and social inclusion. Nevertheless, this is not always carried out in practice and the project, therefore, attempts to identify the factors that explain the health disparities found between persons with ID and the general population. The objective is for patients with ID to be able to make informed decisions about their own health in an autonomous manner.
Health indicators identified by Project Pomona include the following:

1. Demographic indicators: prevalence, type of housing, occupation, socio-economic status / income, life expectancy.

2. Health status indicators: epilepsy, buccal health, body mass index, mental health, auditory and mobility skills.

3. Determinants: physical activity, behavioral problems, psychopharmacological consumption.

4. Health system: hospitalization and contact with health professionals, health check-ups, health promotion, specific training of medical professionals.

\section{Health problems for persons with ID}

In recent years, it has been shown that subjects with ID not only have more health needs than general population, but also that these needs are barely covered and, when they are, the health care received is usually not adequate. Various explanations have been formulated with respect to this lack of care, ${ }^{11}$ such as: lack of knowledge on the part of primary care doctors about common medical problems in the ID population; communication problems when interviewing a patient with ID, especially for those with severe or profound disabilities; and the existing gap in assistance between social services and health services, since nobody in particular is responsible for these individuals.

Kerr and colleagues ${ }^{12}$ state that this population experiences the same health problems as the population without disabilities; but some are more frequent and others are more specifically related to certain syndromes that accompany ID, including:

1. Cancer: Types of cancer most often found in individuals with ID differ with respect to individuals without this disability; there is a higher incidence of gastrointestinal cancers (esophagus, stomach, gall bladder) -two times higher- in patients with ID and, to a lesser extent, malignancies of the lung, prostate, breast and cervix. ${ }^{13}$

2. Coronary disease: Coronary diseases are the second cause of death in persons with ID. ${ }^{14}$ These individuals are more prone to developing hypertension and obesity and exercise is non-existent; all vulnerability factors for cardiac ischemia. Persons with Down syndrome have a greater risk of congenital cardiac disease.

3. Buccodental problems: Subjects with ID are more prone to developing cavities, tooth loss and gum disease and experience a greater number of dental 
extractions. This may be due to dietary deficiency, poor dental hygiene or the inaccessibility of buccal hygiene campaigns to this population; persons with ID rarely visit the dentist. Individuals with Down syndrome possess a higher rate of buccodental problems, such as mouth deformations and gum problems. ${ }^{15}$

4. Diabetes: Persons with ID have a higher rate of diabetes in comparison with the general population. This may be due to the high rate of obesity, poor diets or sedentary lifestyles. ${ }^{16}$

5. Epilepsy: While epilepsy affects $1 \%$ of the population, it affects $33 \%$ of subjects with ID, and the percentage rises with the increased severity of ID. ${ }^{17}$

6. Gastrointestinal problems: Many persons with ID have high levels of Helicobacter pylori, especially those who have lived in institutions or shared residences. ${ }^{18}$ Gastroesophageal Reflux Disease can affect as many as half of the subjects with ID. ${ }^{19}$ This anomaly has been linked with fragile $\mathrm{X}$ syndrome and may be one of the causes for the enormous rates in cancer of the esophagus. In addition, persons with Down syndrome are more prone to colic.

7. Respiratory diseases: This is the leading cause of death in patients with $\mathrm{ID}^{20}$ since they are more vulnerable to respiratory tract infections due to aspiration or reflux, if they have deglutition difficulties. Persons with Down syndrome are at particular risk since they are prone to suffering pulmonary abnormalities, they have a deficient immune system and are likely to breathe through the mouth. ${ }^{21}$ Pulmonary complications have also been reported in subjects with tuberous sclerosis.

8. Sensory problems: Auditory and visual problems are very common in these patients. It is calculated that $40 \%$ have vision problems, and the percentage is similar for auditory problems. In addition, subjects with ID are more prone to develop eye and ear infections, while they less often seek out an ophthalmologist or otorhynolaryngologist. ${ }^{22}$

Table II is a summary of health problems most often related with ID. Of particular interest is the oneyear longitudinal study conducted by the British nongovernmental organization Mencap. ${ }^{23}$ According to this protocol, persons with ID use primary care services significantly less often than the rest of the population. Likewise, it was found that caregivers for these people expressed a great deal of frustration to medical professionals because they seldom referred patients with ID to colleagues in other specialties to meet their health care needs.
Table II

Alterations OFTEN RELATED WITH INTELLECTUAL
DISABILITY (ESPECIALLY SEVERE AND PROFOUND)
System $\quad$ Disorders

\begin{tabular}{ll} 
Buccopharyngeal & $\begin{array}{l}\text { Dental cavities, split palate, gum disease, facial } \\
\text { asymmetries, dislocated jaw }\end{array}$ \\
\hline Sensory & Visual deficits, blindness, hypoacusis, deafness \\
\hline Cardiovascular & $\begin{array}{l}\text { Reduced cardiac and lung functions, especially } \\
\text { linked to curvature of the spine; chronic } \\
\text { respiratory infections; pneumonia }\end{array}$
\end{tabular}

Muscular-skeletal

Curvature of the spine, for example, scoliosis, hyperlordosis, hyperkyphosis; deformities in the shoulders, elbows, hips, hands, knees and feet; hypertony and hypotony;fluctuations in muscular tone, athetosis

\begin{tabular}{ll}
\hline Dermatological & $\begin{array}{l}\text { Tissue damage, especially due to pressure or } \\
\text { incontinence }\end{array}$
\end{tabular}

Excretory Enuresis; encopresis; urinary tract infections; constipation; urinary retention

Central nervous system Epilepsy

\section{Psychiatric and behavioral disorders associated with intellectual disability}

In the last two decades, the problem of mental illness in persons with ID (dual diagnosis) has received increasing attention for two fundamental reasons: a) the recognition of the rights of individuals with ID to receive appropriate medical care; in the past it was quite common that these persons, collectively, were given elevated doses of psychopharmacologic drugs -almost always antipsychotic- when their behavior became unacceptable, without taking into account the diagnosis and collateral and evolutionary effects; and b) the normalization principal is in favor of subjects with ID living in the community and utilizing its resources. In fact, treatment and care of psychiatric disorders in this population is considered to be a fundamental element of community services.

Persons with ID reflect the entire spectrum of psychiatric disorders described in the general population, but the prevalence of mental problems/disorders/illness is higher. In one-third of the cases, ID coexists with psychiatric alterations and recent studies report rates as high as $40 \%,{ }^{24}$ with 10 to $20 \%$ having behavioral problems not related to a mental illness. In $50 \%$ of the 
cases, mental illness goes by undetected or is underdiagnosed, including in institutions with psychological support. ${ }^{25}$

If the situation of persons with ID is analyzed synoptically, the higher proclivity toward psychiatric disorders is not surprising. Publications have shown how biological alterations that often accompany ID are also vulnerability factors for mental illness. One example is the proneness to depression in persons with Down syndrome; it has been suggested that alterations in pair 21 also cause alterations in the dopaminergic system ${ }^{26}$ and, therefore, may contribute to the higher rates seen in mood alterations. Also evident is the way in which many psychological factors in these individuals (such as low self-esteem) are vulnerability factors for mental illness. Lastly, numerous social factors, which unfortunately are very present in this population, increase the proclivity for mental illness, such as rejection, denial of opportunities, abuse, the typically frequent change in caregivers, institutionalization, etc. A more detailed analysis of the above is available in Matson and Sevin's vulnerability factors model..$^{27}$ It is important to remember that, from a biopsychosocial perspective, all of these elements likely interact with each other (table III).

Mental health care for subjects with ID is relatively new and, as a result, much is not known in this area. These theoretical gaps explain the variability that exists among data from epidemiological studies. Some prevalence studies include personality disorders, autism, attention deficit hyperactivity or dementias, but others do not identify them. The same is true with behavioral alterations, which are so frequently seen in this population. Nevertheless, there seems to be a consensus that the pathoplasty of mental illness in patients with ID is often different than that found in the non-disabled population. Depressive mood, for example, may be manifested as behavioral irregularities or irritability, the same symptoms as anxiety. ${ }^{28}$ In these cases, the term used is "behavioral equivalents." Thus, the decision to use diagnostic criteria found in common classifications (CIE-10, DSM-IV-TR), or adapted criteria (Diagnostic Criteria for Learning Disabilities, DC-LD ${ }^{29}$ or DM-ID), ${ }^{30}$ may also result in modifying epidemiological data since many abnormalities do not satisfy sufficient criteria using standard classifications.

Likewise, Sovner ${ }^{31}$ adds the following points as difficulties in evaluating, interpreting and diagnosing the symptoms of psychiatric disorders in persons with ID:

- The presence of disadaptive behavior prior to the mental illness;

\section{Table III}

VULNERABILITY FACTORS IN INTELLECTUAL DISABILITY (Matson and Sevin, 1994)

$\begin{array}{ll}\text { Organic } & \text { Physiological alterations (abnormalities in the cerebral } \\ & \text { structures or epilepsy) } \\ - & \text { Biochemical alterations (prone to the appearance of } \\ & \text { illnesses such as schizophrenia or depression) } \\ - & \text { Genetic alterations (for example, genetic relation } \\ & \text { between Down syndrome and Alzheimer-type } \\ & \text { dementia) }\end{array}$

Behavioral Development of behavior as a result of a complex relationship with the environment (for example, a person isolated from the rest who also presents poor adaptive skills may develop depression)

Developmental Remaining in the maturative or cognitive development of earlier evolutive phases that may predispose the appearance of mental illness (for example, lacking the full formation of the I can predispose the appearance of schizophrenia)

Socio-cultural Stigmatization, lack of opportunities, numerous and marked changes in caregivers, lack of economic resources, abuse, exploitation

- The existence of intellectual limitations that do not allow the patient with ID to understand the evaluator's questions or verbalize an appropriate response.

- The need to situate the symptoms within the context of the evolutive development of the patient. In this respect, Szymanski and King ${ }^{32}$ state that subjects with ID have interpersonal behavior and skills patterns corresponding to earlier chronological stages (for example, infancy) and maintain these characteristics throughout their lifecycle; thus, any attempt to interpret their symptoms should be made in an evolutive context.

- The coexistence of cognitive disorganization in persons with ID that provokes, for example, depression to be manifested by psychotic instead of affective symptoms.

Lastly, another particularly interesting phenomenon for explaining why psychiatric problems in this population go undetected on many occasions is what Reiss calls ID's "diagnostic overshadowing." ${ }^{33}$ This term refers to the tendency by the clinical practitioner to attribute the origin of psychiatric symptoms to ID, which results in masking mental illness; symptoms such as depressive mood and delirium are consequently attributed to ID and not to a mental illness. This impedes the implementation of corrective measures for treating the anomaly. Likewise, a distorted view is 
produced in the mind of the clinician that results in the minimization of the symptoms' importance and, therefore, their diagnostic relevance. Therefore, when an adolescent with normal intelligence displays inappropriate conduct, there is a tendency to regard the subject as having a behavioral problem. If the same inappropriate conduct is displayed by an adolescent with ID, the behavior is presumed to be a result of the disability itself and is, therefore, of less concern than in the first case. Further still, the clinician must often trust reports by third persons in order to establish the diagnosis, which provokes distortions.

Another factor to be considered in ID is the presence of behavioral disorders, recognizable in 25 to $60 \%$ of adults with ID residing in the community; although this percentage decreases to 12 to $17 \%$ when involving severe behavioral irregularities. ${ }^{34,35}$ A behavioral disorder is a set of disruptive of negative behaviors of such intensity, frequency and duration that it can put the physical security of the person or of others in danger, or that may limit or delay the delivery of ordinary community resources. ${ }^{36}$ The principal behavioral problems associated with ID, according to the expanded inventory (Inventory for Client and Agency Planning, ICAP), ${ }^{37}$ are the following: self-injurious behavior, aggressiveness toward or injuring others, destruction of objects, disruptive behavior, atypical and repetitive habits (stereotypical), offensive social conduct, timidity or lack of attention and cooperation. The most frequent type of behavioral problem that requires treatment, needs support and requires changes in daily life is aggressive behavior -whether against others or oneself- especially in young subjects or adolescents who are male.

The differences in prevalence data among the diverse studies are due to the various definitions of behavioral problems, the utilization of different lists for problematic behaviors, difficulty determining the group of persons who truly represent a challenge for services, and reliability problems from one observer to another because of variations in the criteria used for severity among professionals who treat the same persons.

Finally, it is important to recognize the relation between behavioral problems and mental illness. It is possible to point to the study by Rojahn and colleagues, ${ }^{38}$ that uses the Behavioral Problems Inventory scales and Diagnostic Assessment for the Severely Handicapped-II. This protocol finds that subjects with severe or profound ID who displayed self-injurious, stereotyped or aggressive and destructive behavior generally had higher psychopathology scores; in addition, the presence of behavioral problems tripled the probability of the appearance of almost all of the psychiatric disorders.

\section{Conclusion: What can health sciences do for persons with intellectual disability?}

Medicine and health sciences in general should contribute to improving the quality of life of individuals with ID; to accomplish this, it is possible to design interventions that are closely related with the diagnosis. ${ }^{39}$ All available information about possible etiological factors must be taken into account (for example, precipitating episodes, family disposition, specific biological deficits, personality problems and specific developmental difficulties). Factors such as the severity of the ID, related disorders, the effects of prior treatments and the social environment should also be considered. Due to the complexity of ailments in persons with ID, their treatment must be planned from diverse perspectives (pharmacology, psychotherapy, behavioral intervention, etc.). In this regard, Ferrell and colleagues ${ }^{40}$ propose a combined therapeutic model based on community support, along with neuropsychiatric measures, as a type of effective intervention for psychiatric and behavioral problems in persons with ID.

Nevertheless, for a long time the only medical response to the problems experienced by subjects with ID has been the unrestricted provision of antipsychotics for the control of behavioral problems, as well as institutionalization of this individuals in psychiatric institutions; this has generated rejection of and generally discredited psychopharmacology in this field. Currently, there are consensual guidelines and recommendations for the psychopharmacological treatment of this population. ${ }^{39,41}$ Contributions by the Royal College of Psychiatrists, Birmingham University and the Mencap Association should be noted, ${ }^{42}$ who have developed a set of indications for psychopharmacological treatment and reviewed the scientific evidence.

Prescribing doses and guidelines are the same as those that apply to the general adult population, though increases in and the suspension of medications should occur over a longer period of time. In the case of psychotic and severe behavioral disorders in which an environmental, organic or affective cause has been ruled out, the atypical antipsychotics that have been studied the most in this population are risperidone, followed by olanzapine ${ }^{28}$ (a second choice is haloperidol and, third, clozapine, while taking into account leukogram values). Table IV lists some general indications.

The principal problem faced by a medical professional when considering the psychopharmacological treatment of mental disorders in the ID population is the variability of syndromes. This situation, in turn, provokes different medical, psychiatric and behavioral symptoms as compared to the general population, which 
entails enormous difficulties in establishing a psychiatric diagnosis, determining a prognosis for standard treatments, and detecting possible undesirable effects and adverse reactions to medication. Added to this is the scarcity of specific studies about the effectiveness and safety of using psychopharmacological medications in patients with ID. Nearly all are single-case studies, case series, retrospective reviews and open trials.

Furthermore, the results of controlled studies with heterogeneous samples of persons with ID are suspect, since the biological differences between a person with Down syndrome and another with Angelman syndrome, for example, are much greater than those observed between adults in the general population. In fact, controlled trials should be conducted in subjects with the same or similar etiological diagnosis. Another factor that should not be overlooked is the enormous individual variability in the response to and appearance of secondary effects in these patients and the lack of acute and subacute facilities for individuals in crisis, in such a way as to be able to control therapeutic guidelines.

It is reasonable to act with extreme caution, make an appropriate diagnosis, implement individualized therapeutic changes (without modifying several medication regimens at one time) and instruct the patient's family in accordance with national guidelines. In this respect, it is also worth remembering the old four rules

Table IV

Psychopharmacological RECOMMENDATIONS FOR INTELLECTUAL DISABILITY

\begin{tabular}{|c|c|c|}
\hline Medication & Symptoms & Observations \\
\hline Antipsychotics & $\begin{array}{l}\text { Psychotic symptoms } \\
\text { Self-injurious behavior } \\
\text { Behavioral problems }\end{array}$ & $\begin{array}{l}\text { Atypical antipsychotics are } \\
\text { preferable (risperidone) } \\
\text { Depot antipsychotics if there } \\
\text { is no treatment observation }\end{array}$ \\
\hline Mood stabilizers & $\begin{array}{l}\text { Bipolar disorder } \\
\text { Mania episode } \\
\text { Aggressive behavior } \\
\text { Agitation } \\
\text { Psychiatric or behavioral } \\
\text { problems in patients with } \\
\text { epilepsy }\end{array}$ & $\begin{array}{l}\text { Valproic acid or lithium for } \\
\text { bipolar disorder; in agita- } \\
\text { tion cases also use SSRI* } \\
\text { antidepressants or atypical } \\
\text { antipsychotics }\end{array}$ \\
\hline Antidepressants & $\begin{array}{l}\text { Depression } \\
\text { Suicidal ideation/behavior } \\
\text { Self-injurious behavior } \\
\text { Aggressive behavior } \\
\text { Agitation, anxiety }\end{array}$ & $\begin{array}{l}\text { Use of SSRI preferred; evalu- } \\
\text { ate use of delayed action in } \\
\text { case of anxiety } \\
\text { Also use benzodiacepines; in } \\
\text { case of suicidal ideation/be- } \\
\text { havior, also administer mood } \\
\text { stabilizers }\end{array}$ \\
\hline
\end{tabular}

* SSRI: Selective Serotonin Reuptake Inhibitors for medical treatment by Cecil Loeb: a) if the prescribed treatment works, don't change it; $b$ ) if the prescribed treatment does not work, suspend it; c) if you do not know what to do, do not do anything; d) whatever you do, do not let your patient wind up in the hands of the surgeon!

In response to the high degree of unsatisfied health needs in the ID population, the following action steps have been suggested: ${ }^{43}$

1. Preparation: familiarization and knowledge of places (hospital, medical office), procedures and medical techniques.

2. Longer consultation time: with the goal of enabling persons with ID to discuss their health problems.

3. Informal and non-threatening environment: modifying the environment in order to attain a nonthreatening space that helps to reduce the stress and anxiety felt by these patients in a situation such as a doctor's visit.

The U.S. Public Health Service published a report in $2002^{44}$ that highlighted general lines of action in the field of ID for health services:

1. Integrate the promotion of health for persons with ID into community health care environments.

2. Increase knowledge about health factors related to ID and put into practice this knowledge.

3. Improve the quality of health care for patients with ID.

4. Institute training programs for professionals who provide health care to subjects with ID.

5. Guarantee that the health system produces good health indicators and results for persons with ID.

6. Increase the accessibility of health services to individuals with ID.

In Europe, similar recommendations have been developed. ${ }^{45}$ This all leads to laying the groundwork so that in the near future the health sciences will give ID the consideration needed by this group.

\section{References}

I. Schalock RL, Luckasson RA, Shogren KA, Borthwick-Duffy S, Bradley $\mathrm{V}$, Buntinx $\mathrm{WH}$, et al. The renaming of mental retardation: understanding the change to the term intellectual disability. Intellect Dev Disabil 2007;45(2): I I6-124.

2. Salvador-Carulla L, Bertelli M. Mental retardation or intellectual disability: time for a conceptual change. Psychopathology 2008;4I:I0-I6. 3. Durkin M.The epidemiology of developmental disabilities in low-income countries. Ment Retard Dev Disabil Res Rev 2002;8(3):206-2I I. 
4. Polder J], Meerding W], Bonneux L, van der Maas PJ. Healthcare costs of intellectual disability in the Netherlands: a cost-of-illness perspective. J Intel Disabil Res 2002;46(Pt 2): 168-178.

5.American Association on Mental Retardation (AAMR). Mental retardation: definition, classification and systems of supports. IOth ed.Washington, D.C.: American Association on Mental Retardation (AAMR); 2002.

6. Zigler E. Can we "cure" mild mental retardation among individuals in the lower socioeconomic stratum? Am J Public Health 1995;85(3):302-304.

7. Ouellette-Kuntz H, Garcin N, Lewis ME, Minnes P, Martin C, Holden JJ. Addressing health disparities through promoting equity for individuals with intellectual disability. Can J Public Health 2005;96(Suppl 2):S8-22. 8. Flint J,Yule W. Behavioural phenotypes. In: Rutter M, Taylor E, Hersov L, editors. Child and adolescent psychiatry. Oxford: Blackwell Science; 1994. p. 666-687.

9.American Psychiatric Association (APA). Manual diagnóstico y estadístico de los trastornos mentales. 4th ed. (revised text). DSM-IVTR. Barcelona: Masson; 2002.

I0.Walsh PN, Kerr M, van Schrojenstein Lantman-de Valk HM. Health indicators for people with intellectual disabilities: a European perspective. Eur J Public Health 2003; I3(Suppl 3):47-50.

II. Rodgers J. Primary health care provision for people with learning difficulties. Health Soc Care Comm 1994;2(I):II-I7.

12. Kerr MP. Primary health care for people with an intellectual disability. J Intel Disabil Res 1997;4I(5):363-364.

13. Cooke LB. Cancer and learning disability. J Intel Disabil Res 1997;4 I (Pt 4):312-316.

14. Hollins S,Attard MT, von Fraunhofer N, McGuigan S, Sedgwick P. Mortality in people with learning disability: risks, causes, and death certification findings in London. Dev Med Child Neurol 1998;40(I):50-56. 15. Cumella S, Ransford N, Lyons J, Burnham H. Needs for oral care among people with intellectual disability not in contact with Community Dental Services.J Intel Disabil Res 2000;44(Pt I):45-52.

16. Butler JV, Whittington JE, Holland AJ, Boer H, Clarke D, Webb T. Prevalence of, and risk factors for, physical ill-health in people with Prader-Willi syndrome: a population-based study. Dev Med Child Neurol 2002;44(4):248-255.

17. Airaksinen EM, Matilainen R, Mononen T, Mustonen K, Partanen J, Jokela $\mathrm{V}$, et al.A population-based study on epilepsy in mentally retarded children. Epilepsia 2000;4I(9):I2I4-I220.

I8. Bohmer C], Klinkenberg-Knol EC, Kuipers E], Niezen-de Boer MC, Schreuder H, Schuckink-Kool F, et al. The prevalence of Helicobacter pylori infection among inhabitants and healthy employees of institutes for the intellectually disabled.Am J Gastroenterol 1997;92(6): 1000-1004. 19. Bohmer CJ, Niezen-de Boer MC, Klinkenberg-Knol EC, Deville WL, Nadorp JH, Meuwissen SG. The prevalence of gastroesophageal reflux disease in institutionalized intellectually disabled individuals. Am J Gastroenterol 1999;94(3):804-8I0.

20. Janicki MP, Dalton AJ, Henderson CM, Davidson PW. Mortality and morbidity among older adults with intellectual disability: health services considerations. Disabil Rehabil 1999;2I (5-6):284-294.

21. Hilton JM, Fitzgerald DA, Cooper DM. Respiratory morbidity of hospitalized children with trisomy 21.J Paediatr Child Health 1999;35(4):383-386.

22. Schrojenstein Lantman-de Valk HM, van den AM, Maaskant MA, Haveman MJ, Urlings HF, Kessels AG, et al. Prevalence and incidence of health problems in people with intellectual disability.J Intel Disabil Res 1997;4I (Pt I):42-5I.

23. Band R. The NHS: health for all? Londres: Mencap National Centre; 1998. 24. Cooper SA, Smiley E, Finlayson J, Jackson A,Allan L, Williamson A, et al.The prevalence, incidence, and factors predictive of mental ill-health in adults with profound intellectual disabilities. Prospective study. J Appl Res Int Dis 2007;20:493-50 I.

25. Salvador-Carulla L, Rodríguez-Blazquez C, Rodriguez DM, Perez-Marin J,Velazquez R. Hidden psychiatric morbidity in a vocational programme for people with intellectual disability. Intel Disabil Res 2000;44(Pt 2):147-154

26. Collacott RA, Cooper SA, McGrother C. Differential rates of psychiatric disorders in adults with Down's syndrome compared with other mentally handicapped adults. Br J Psychiatry 1992;161:671-674. 27. Salvador-Carulla L, Novell R. Guía práctica de la evaluación psiquiátrica en el retraso mental. Barcelona: Aula Médica; 2002.

28. Hemmings CP, Gravestock S, Pickard M, Bouras N. Psychiatric symptoms and problem behaviours in people with intellectual disabilities. J Intel Disabil Res 2006;50(Pt 4):269-276.

29. Royal College of Psychiatrists. Diagnostic criteria for psychiatric disorders for use with adults with learning disabilities/mental retardation, DC-LD. London: Royal College of Psychiatrists; 200I.

30. Fletcher R, Loschen E, Stavrakaki C, First M. Diagnostic ManualIntellectual Disability (DM-ID): a textbook of diagnosis of mental disorders in persons with intellectual disability. Kingston, NY: NADD Press; 2007.

31. Sovner R. Limiting factors in the use of DSM-III criteria with mentally ill/mentally retarded persons. Psychopharmacol Bull 1986;22(4): 1055-1059. 32. Szymanski L, King BH. Practice parameters for the assessment and treatment of children, adolescents, and adults with mental retardation and comorbid mental disorders. American Academy of Child and Adolescent Psychiatry Working Group on Quality Issues. J Am Acad Child Adolesc Psychiatry 1999;38(I2 Suppl):5S-3IS.

33. Reiss S, Levitan GW, Szyszko J. Emotional disturbance and mental retardation: diagnostic overshadowing.Am J Ment Defic 1982;86(6):567-574. 34. Emerson E, Bromley J.The form and function of challenging behaviours. J Intel Disabil Res 1995;39(Pt 5):388-398.

35. Novell R, Salvador-Carulla L. Problemas de conducta en el retraso mental. Siglo Cero Rev Esp Discap Intel 2003;34:78-86.

36. Emerson E, Barrett S, Bell C, Cummings R, McCool C, Toogood A, et al. Developing services for people with severe learning disabilities and severe challenging behaviours. Canterbury: University of Kent at Canterbury, Institute of Social and Applied Psychology; 1987.

37. Bruininks RH, Hill BH,Weatherman RF,Woodcock RW. Inventory for client and agency planning, ICAP.Allen, TX.: DLM Teaching Resources; 1986. 38. Rojahn J, Matson JL, Naglieri JA, Mayville E. Relationships between psychiatric conditions and behavior problems among adults with mental retardation. Am J Ment Retard 2004;109(1):21-33.

39. Grey IM, Hastings RP. Evidence-based practices in intellectual disability and behaviour disorders. Curr Opin Psychiatry 2005; 18(5):469-475. 40. Ferrell RB, Wolinsky EJ, Kauffman Cl, Flashman LA, McAllister TW. Neuropsychiatric syndromes in adults with intellectual disability: issues in assessment and treatment. Curr Psychiatry Rep 2004; 6(5):380-390. 4I. Bokszanska A, Martin G,Vanstraelen M, Holt G, Bouras N, Taylor D. Risperidone and olanzapine in adults with intellectual disability: a clinical naturalistic study. Int Clin Psychopharmacol 2003;|8(5):285-29I.

42. Deb S, Clarke D, Unwin G. Using medication to manage behaviour problems among adults with a learning disability. Quick reference guide. Birmingham: University of Birmingham, Royal College of Psychiatrists and Mencap; 2006.

43. Kandel I, Morad M, Merrick J. Health Needs Assessment Report: people with learning disabilities in Scotland.J Pol Prac Intel Disabil 2004; I (2): I I3-I I4.

44. U.S. Public Health Service. Closing the gap: a national blueprint for improving the health of individuals with mental retardation. Report of the surgeon general's conference on health disparities and mental retardation. Washington, D.C.: U.S. Public Health Service; 2002.

45. Dosen A, Bouras N, Bradl C, Salvador-Carulla L, Efthimiopoulou G, et al. Functional Rehabilitation: Supporting Persons with Mental Retardation. Working Group 3; Helios II Programme 1993-1996. Brussels: European Commission; 1997. 